\section{Electrical Stimulation of the Human Cochlea}

IT has been shown by Jellinek and Scheiber ${ }^{1}$, and since confirmed ${ }^{2,3,4}$, that stimulation of the human cochlea by audio-frequency alternating currents results in a sensation of tone corresponding in pitch to the frequency of the stimulus. The possibility that the mechanism of excitation is by direct stimulation of the cochlear nerve fibrils has an important bearing upon existing views on audition, in so far as it would provide clear evidence in support of the 'telephone' theory. It has been suggested as an alternative possibility that the electrical currents excite the nerve elements indirectly by setting in motion, in a manner not understood, those cochlear elements which are normally set in motion by physiologically applied sound waves. Such a mechanism of excitation would imply localization of the response according to frequency by resonance, and so would make possible an explanation of the observed phenomena upon the basis of the Helmholtz resonance hypothesis. This 'movement' theory of excitation is strongly supported by experimental evidence which is now described. As stated by Hartridge ${ }^{5}$, sudden reversal in the phase of a continuous musical tone results in the human subject in a sensation described as a 'phase change beat'. This, in accordance with the resonance hypothesis, has been correlated with a transient arrest of the basilar fibres due to the opposition of the applied force following the phase reversal to the after swings due to resonance. Further, objective evidence of the occurrence of such an arrest has been provided by a recent study of the auditory tract potentials in the cat ${ }^{6}$.

In the light of these findings, it has been considered justifiable to attribute the 'phase change beat' to the intervention of resonant moving parts between the nervous elements and the applied stimulus. The experimental demonstration of the occurrence of a 'phase change beat' in response to an electrical stimulus undergoing periodic phase reversal would therefore clearly be subject to the same explanation and so support the 'movement' theory of excitation. Stimulation of the human ear upon these lines has accordingly been carried out. The electrical output of the phase-reversing photo-electric siren already described $^{6}$ was used at a frequency of $1,024 \sim$ with leads to the external auditory meatus (filled with saline) and to a metal plate on the forearm.

Under these conditions the phase change beat was found to be clearly observable. Further, the beat was heard at an intensity some $8 \mathrm{db}$. above that of the threshold for perception of the tone itself. This difference was found to approximate closely to that observed when the phase-reversing stimulus was applied to the ear mechanically, namely, by means of a moving-coil loud-speaker. This correspondence is considered to provide further evidence that the mechanism of excitation involved in the normal mode of audition is similarly involved by electrical stimulation. In addition, observations have been made upon the response of the human ear to interruptions of four and ten cycles duration in continuous tones of $1,024 \sim$. Here also the stimulus was generated by a suitable modification of the photo-electric siren and was applied to the ear electrically and also by means of the moving-coil loud-speaker.

With an interruption of four cycles duration, the beat due to the interruption was observed at an intensity some $18 \mathrm{db}$. above that of the threshold for the tone itself. With an interruption of ten cycles duration, the difference between the beat and tone thresholds was smaller (10 db.), in accordance, presumably, with a change in ratio of the factors of intensity and duration of interruption which govern perception of the flicker of sound.

In all cases, the differences in threshold for tone and beat observed with the electrical mode of stimulation were found to approximate closely to the corresponding differences found by the mechanical mode represented by the loud-speaker method of stimulation.

This finding must again be considered to provide confirmation of the movement theory of excitation of the human cochlea by audio-frequency electrical stimulation.

\section{Ferens Institute of Otology,}

C. S. HaLlipike.

Middlesex Hospital, W.1,

and Dept. of Physiology,

St. Bartholomew's Medical College,

\section{E.C.1. \\ Jan. 14.}

1 Jellinek, S., and Scheiber, T., Wien. Klin. Woch., 43, 417 (1930).

${ }^{2}$ Perwitzschky, R., Z. Hals, Nasen, und Ohrenheilk., 26, 477 (1930).

${ }^{3}$ Fromm, B., Nylén, O., and Zottermann, Y., J. Physiol., 80, 3P (1933).

4 Gersuni, G. V., Volokhov, A. A., J. Physiol. U.S.S.R., 17, 1259 (1934).

5 Hartridge, H., Brit. J. Psychol., 12, 142 (1921).

- Hallpike, C. S., Hartridge, H., and Rawdon-Smith, A. F., Proc. Roy. Soc. (in the press).

\section{Sir Grafton Elliot Smith and Work on Early Man in China}

Is looking back over the history of the research on early man in China, it is of interest to realize how precarious was the adventure we entered upon. At the present time, we have five more or less complete skulls, four large skull-fragments, twelve mandibles, and nearly one hundred isolated teeth-indeed an imposing 'sum' of specimens of Sinanthropus. However, the impressive point in this history is the fact that the vital generic characteristics of the distinct hominid were deduced from a diagnosis based, not upon this large number of specimens, but upon one single molar tooth. This specimen, which heralded a period of great scientific activity, was placed at our disposal in 1927 by the late Dr. Davidson Black.

After this birth of Sinanthropus, on account of the dearth of material and the difficulty of drawing conclusions from one isolated tooth, Dr. Black's claims were not everywhere accepted. It was Sir Grafton Elliot Smith who, as an authority in the field of early man, first accepted Sinanthropus as a distinct genus of the hominid; and it was Sir Grafton Elliot Smith who gave the needed support and impetus to Dr. Black, which encouraged him to carry on his scientific explorations in China.

The discovery of a skull in 1929 proved that Sinanthropus was not a product of Dr. Black's imagination, but that on the contrary he had been quite justified in his classification of a new genus in human palæontology. In November 1930, the Cenozoic Research Laboratory of the National Geological Survey of China invited Sir Grafton to take the long journey to the Far East in order to examine the new specimens and to visit the very site from which they had been taken. Thus it was Sir Grafton who, among all the anthropologists from outside the laboratory, was the first to handle the skull and to discuss it with Dr. Black. 